\title{
APLIKASI MATRIKS CONDITION SURVEY PROTOCOL (CSP)1 DALAM PENILAIAN KEADAAN BANGUNAN SEKOLAH: ANALISIS PENGKADARAN KESELURUHAN KEADAAN BANGUNAN
}

\author{
M. Mahli, A.I Che-Ani, N.M. Tawil, M.Z. Abd-Razak, N.A.G. Abdullah \\ Jabatan Seni Bina, Fakulti Kejuruteraan dan Alam Bina \\ Universiti Kebangsaan Malaysia
}

\begin{abstract}
Abstrak
Penyenggaraan merupakan aktiviti yang sangat penting bagi mengekalkan nilai aset bangunan sekolah, di samping menyediakan persekitaran yang kondusif bagi tujuan pengajaran dan pembelajaran. Bagi melaksanakan aktiviti penyenggaraan bangunan, pemeriksaan terhadap keadaan semasa bangunan adalah perlu. Ini bertujuan untuk mendapatkan maklumat mengenai kondisi bangunan dan penilaian yang bersistematik dapat dilaksanakan. Kertas ini membincangkan kajan terhadap keadaan bangunan sekolah rendah di bahagian Kuching, Sarawak yang telah dilaksanakan dengan menggunakan Matriks Condition Survey Protocol (CSP)1 sebagai alat pengukur. Selain itu, kajian ini juga bertujuan menilai perkaitan antara usia sekolah dengan bilangan kerosakan bangunan, markah keseluruhan dan pengkadaran bagi setiap sekolah Tiga perkara utama dikenalpasti melalui analisis Matriks CSP1 iaitu bilangan keseluruhan kerosakan bangunan, markah keseluruhan kerosakan bangunan dan pengkadaran keseluruhan bagi setiap sekolah. Analisis yang dijalankan terhadap 24 buah sekolah mendapati terdapat 4,725 kerosakan keseluruhan bangunan sekolah, markah keseluruhan yang diperolehi adalah 45,868 manakala pengkadaran keseluruhan bagi semua sekolah adalah 9.71, iaitu berada pada tahap yang sederhana teruk. Hasil kajian mendapati ketiga-tiga aspek tersebut adalah berkaitan dengan usia sekolah. Ini menyokong teori bahawa semakin tinggi usia sekolah, semakin banyak kerosakan bangunan yang berlaku.
\end{abstract}

\subsection{Pengenalan}

Bangunan adalah aset utama untuk semua jenis organisasi termasuklah sektor awam. Kepentingan aset sama seperti manusia, kewangan dan sumber informasi, yang mana ia dapat menyumbang kepada kejayaan sesuatu organisasi apabila diuruskan secara efektif dan efisien. Bagi mengekalkan nilai sesuatu aset, ia perlulah diuruskan secara profesional. Telah terbukti bahawa bukan sahaja jumlah modal yang besar dapat memastikan nilai aset dapat dikekalkan, tetapi aset juga boleh bertambah melalui pengurusan aset yang efektif dan kreatif. Biasanya, tanggungjawab menjaga harta benda awam di Malaysia termasuklah sekolah awam telah diagih-agihkan kepada beberapa jabatan kerajaan dan selalunya dilaksanakan secara reaktif. Penyelidikan ini memfokuskan kepada penilaian keadaan bangunan sekolah, yang merupakan salah satu proses utama dalam kitar hayat pengurusan aset menyeluruh dan pengurusan fasiliti. Penilaian ini adalah penting supaya aset bangunan berupaya menyokong operasi teras sesebuah sekolah, yang perlu beroperasi secara efisien dan efektif di dalam menyediakan persekitaran pembelajaran yang berkualiti kepada pelanggan utama sekolah, iaitu para pelajar.

Kertas ini membincangkan mengenai penilaian keadaan bangunan sekolah berdasarkan analisis Matriks CSP1. Kandungan kertas ini adalah pengenalan, kajian literatur, bahan dan kaedah, keputusan dan perbincangan serta kesimpulan penyelidikan. 


\subsection{Kajian Literatur}

Kerja-kerja penyenggaraan bangunan dan kemudahan yang terdapat di sekolah adalah berada di bawah tanggungjawab bahagian penyenggaraan. Menurut Syamilah (2005), aspek penyenggaraan bangunan dan sekolah biasanya diabaikan kerana kurangnya pengetahuan dan kurang memahami peranan penyenggaraan di dalam sesebuah organisasi. Tambahan pula di Malaysia garis panduan bagi pengurusan penyenggaraan dan juga pengukuran bagi prestasi sistem yang digunapakai adalah kurang jelas (Nik Elyna et al. 2011).

Penyenggaraan bangunan sekolah merangkumi aktiviti mengekalkan kemudahan sekolah supaya sentiasa dalam keadaan yang baik. Walaupun sesetengah bangunan yang baru dibina masih berada dalam keadaan baik dan mampu menaiktaraf kemudahan pembelajaran serta menyediakan persekitaran yang lebih berkualiti, ia tidak akan sentiasa kekal baru sepanjang jangka hayatnya (Abdul Lateef et al. 2011). Ini kerana semua fasiliti semakin berusia dan sentiasa berlaku proses ubahsuai dan baik pulih (Nik Elyna et al. 2011). Lebih serius, masalah berkaitan penyenggaraan juga ada kalanya terjadi sebelum bangunan siap dibina (Nik Elyna et al. 2011). Fasiliti sekolah termasuklah pejabat, bilik kakitangan, kelas, perpustakaan, makmal, kantin, dewan, bengkel, asrama, makmal komputer, kediaman kakitangan, padang dan lain-lain. Di dalam menguruskan atau mengekalkan prestasi semua kemudahan ini, penilaian keadaan adalah salah satu langkah proaktif yang boleh diimplementasikan.

Keadaan bangunan sekolah mempunyai hubungan yang signifikan dengan pencapaian pelajar (Uline \& TschannenMoran 2008). Tambah Schneider (2002), aspek fizikal persekitaran sekolah boleh memberikan kesan terhadap pengajaran dan pembelajaran, sama ada membantu atau merencatkan proses tersebut. Faktor ini termasuklah aspekaspek seperti konfigurasi ruang, kualiti udara dalaman, pengudaraan, keselesaan termal, pencahayaan dan bunyi. Pendapat ini disokong oleh Uline et al. (2009) yang mendapati bahawa personaliti tertentu ruang-ruang yang berbeza mampu menggalakkan perasaan memiliki dan mewujudkan komitmen untuk berkongsi matlamat pembelajaran. Perkara-perkara yang berkaitan dengan kualiti bangunan pula menjadi pusat interaksi antara persekitaran binaan dengan pengguna bangunan termasuklah pergerakan, estetik, pencahayaan, kelas yang fleksibel dan responsif, kawasan terbuka dan soal keselamatan (Uline et al. 2009).

Hubungan antara keadaan bangunan sekolah dengan pencapaian pelajar dijelaskan oleh Uline dan Tschannen-Moran (2008) yang menegaskan bahawa pelajar-pelajar dari sekolah yang mempunyai kualiti keadaan persekitaran yang lebih baik menunjukkan pencapaian yang lebih tinggi. Manakala bangunan sekolah yang uzur dan tidak memenuhi keperluan pengguna merupakan persekitaran yang boleh membantutkan proses pengajaran dan pembelajaran (Uline dan Tschannen-Moran 2008). Kenyataan di atas menyokong kesimpulan yang dibuat oleh Schneider (2003) yang menyatakan bahawa fasiliti sekolah mempunyai kesan secara langsung terhadap pengajaran dan pembelajaran. Fasiliti sekolah yang baik dapat disediakan jika terdapat pembiayaan yang mencukupi serta reka bentuk, pembinaan dan penyenggaraan yang cekap (Schneider 2002). 
Dipetik daripada satu laporan yang dikeluarkan oleh United States Government Accountability Office (GAO) pada bulan Mac 2011, secara tipikalnya kos operasi dan penyenggaraan menelan belanja antara $60 \%$ hingga $80 \%$ kos sesuatu fasiliti sepanjang jangka hayatnya. Sementara itu, kos yang diperlukan untuk mereka bentuk dan membina fasiliti hanya lebih kurang 5\% hingga 10\% (GAO 2011). Jumlah tersebut menunjukkan perbezaan yang ketara antara kos yang diperlukan untuk operasi dan penyenggaraan sesuatu fasiliti berbanding kos untuk mereka bentuk dan membina fasiliti tersebut. Selain itu, laporan tersebut juga turut mendedahkan bahawa terdapat kelemahan dalam urusan penyenggaraan aset yang dilaksanakan oleh pihak kerajaan (GAO 2011).

Berdasarkan laporan tersebut, jelas bahawa pemeriksaan bangunan sekolah amat penting bagi mengenal pasti kerosakan bangunan sekolah sebelum kerosakan tersebut menjadi lebih parah. Ini dapat mengurangkan kos yang diperlukan untuk menyenggara bangunan apabila kerosakan tersebut merebak dan menjadi semakin parah. Di samping itu, kerja-kerja pemeriksaan dan pengurusan penyenggaraan sekolah juga perlu dilakukan oleh golongan profesional atau agensi-agensi tertentu. Ini kerana pihak kerajaan mungkin sukar untuk memantau, memeriksa dan menyenggara kesemua bangunan sekolah kerana jumlahnya yang tinggi serta tiada kepakaran dalam bidang tersebut.

\subsection{Bahan Dan Kaedah Penyelidikan}

Data yang diperlukan bagi penilaian ini diperolehi melalui kerja ukur kondisi keadaan bangunan sekolah. Sampel penyelidikan ini tertumpu kepada sekolah rendah jenis kebangsaan di bahagian Kuching, Sarawak. Kerja-kerja pengumpulan data di analisis menggunakan Matriks CSP1.

\subsection{Sampel penyelidikan}

Terdapat 134 buah sekolah rendah kebangsaan di bahagian Kuching (Kementerian Pelajaran Malaysia, Jun 2010). Kriteria pensampelan yang digunakan adalah bersandarkan kepada usia sekolah, yang merujuk kepada bangunan pertama yang dibina untuk sekolah tersebut. Usia sekolah adalah daripada 1 tahun sehingga 65 tahun.

Penyelidikan ini menggunakan dua kaedah pensampelan iaitu rawak mudah dan berstrata. Pensampelan rawak mudah digunakan kerana populasi liputan penyelidikan hanya berada di bahagian Kuching dan rangka pensampelan sekolah boleh diwujudkan. Manakala penggunaan kaedah pensampelan berstrata adalah disebabkan setiap elemen yang terdapat dalam populasi penyelidikan boleh dibentuk kepada beberapa non-overlapping strata yang bermakna. Berdasarkan daripada taburan usia bangunan sekolah, sebanyak 11 non-overlapping strata telah dibentuk, iaitu;

$\begin{array}{cl}\text { i. } & \text { Kurang daripada } 6 \text { tahun } \\ \text { ii. } & 6 \text { hingga } 10 \text { tahun } \\ \text { iii. } & 11 \text { hingga } 15 \text { tahun } \\ \text { iv. } & \text { 16 hingga } 20 \text { tahun } \\ \text { v. } & 21 \text { hingga } 25 \text { tahun }\end{array}$



vi. $\quad 26$ hingga 30 tahun
vii. $\quad 31$ hingga 35 tahun
viii. $\quad 36$ hingga 40 tahun
ix. $\quad 41$ hingga 45 tahun
x. $\quad 46$ hingga 50 tahun
xi. Lebih daripada 50 tahun

Variable of selection (VOS) yang digunakan dalam pengiraan saiz sampel ialah kadar usia sesebuah sekolah. Faktor-faktor lain yang digunakan adalah aras keyakinan sebanyak 90\% atau dengan kata lain, 90\% daripada anggaran yang dikeluarkan daripada sampel ini boleh dipercayai pada peringkat rekabentuk yang dikehendaki. Selain daripada itu, ralat margin (margin of error) pula dikawal sebanyak $15 \%$.

Kaedah pengiraan saiz sampel bagi penyelidikan ini adalah menggunakan formula Simple Random Sampling (SRS). Pengiraan saiz sampel dikira menggunakan formula berikut:

$$
n=\frac{n_{0}}{1+\frac{n_{0}}{N}}
$$

Yang mana:

$$
n_{0}=\frac{z^{2} p q}{d^{2}}
$$

Di mana:

$$
\begin{array}{ll}
n & \text { - saiz sampel keseluruhan } \\
n_{0} & \text { - saiz sampel minima yang diperoleh menggunakan kaedah SRS } \\
N & \text { - jumlah populasi } \\
d & \text { - margin ralat } \\
z & \text { - nilai Z (taburan normal) untuk paras keyakinan yang ditetapkan } \\
p & \text { - kadar kejayaan memperoleh bangunan sekolah berusia lebih daripada } 25 \text { tahun }
\end{array}
$$

Dalam penyelidikan ini, unit pensampelan ialah sekolah dan responden yang memberikan maklumat berkenaan sekolah adalah pihak pengurusan sekolah dan keadaan fizikal semasa bangunan sekolah. Pengiraan saiz sampel menggunakan formula SRS adalah seperti berikut:

$$
n=\frac{n_{0}}{1+\frac{n_{0}}{N}}=\frac{29.9587}{1+\frac{29.9587}{134}}=24.5
$$


iaitu:

$n_{0}=\frac{z^{2} p q}{d^{2}}=\frac{(1.645)^{2}(0.53)(0.47)}{(0.15)^{2}}=29.9587$

Berdasarkan pengiraan tersebut, sejumlah 24 sampel dipilih dalam penyelidikan ini. Memandangkan setiap strata usia bangunan adalah berbeza mengikut saiz, langkah untuk mengubahsuai kebarangkalian dalam memilih strata perlu dilakukan. Untuk itu, strata yang mempunyai bilangan yang banyak mempunyai kebarangkalian yang lebih tinggi dipilih manakala strata yang mempunyai bilangan yang sedikit mempunyai kebarangkalian yang kecil untuk dipilih. Kaedah ini dinamakan sebagai Kebarangkalian Berkadaran Mengikut Saiz (Probability Proportional to Size). Saiz sampel berkadaran mengikut saiz strata adalah seperti dalam Jadual 1.

Jadual 1 :Saiz sampel yang terpilih mengikut usia sekolah

\begin{tabular}{ccccc}
\hline Usia sekolah & Bilangan sekolah & Kadar & $\begin{array}{c}\text { Anggaran Saiz } \\
\text { sampel }\end{array}$ & Saiz sampel \\
\hline $0-5$ & 15 & 0.11 & 2.80 & 3 \\
$6-10$ & 13 & 0.10 & 2.43 & 2 \\
$11-15$ & 12 & 0.09 & 2.24 & 2 \\
$16-20$ & 6 & 0.04 & 1.12 & 1 \\
$21-25$ & 16 & 0.12 & 2.99 & 3 \\
$26-30$ & 6 & 0.04 & 1.12 & 1 \\
$31-35$ & 17 & 0.13 & 3.17 & 3 \\
$36-40$ & 11 & 0.08 & 2.05 & 2 \\
$41-45$ & 20 & 0.15 & 3.73 & 4 \\
$46-50$ & 8 & 0.06 & 1.49 & 1 \\
$51+$ & 10 & 0.07 & 1.87 & 2 \\
\hline \multicolumn{5}{r}{}
\end{tabular}

Bagi tujuan pemilihan sampel, rangka pensampelan yang menyenaraikan semua sekolah mengikut usia bangunan liputan penyelidikan adalah disediakan. Dengan menggunakan jadual nombor rawak, bilangan sekolah mengikut saiz sampel dapat diperolehi dan kaedah pensampelan tanpa penggantian digunakan untuk tujuan ini.

\subsection{Pengutipan Data}

Aspek pemeriksaan bagi kerja ukur kondisi bangunan sekolah rendah dibahagikan kepada tiga iaitu aspek luaran (fasad), aspek dalaman dan bumbung. Aspek luaran ini terdiri daripada komponen-komponen bangunan yang dapat dilihat tanpa memasuki ruang-ruang di dalam bangunan seperti keadaan fasad bangunan, koridor, dan kemasan dinding bangunan seperti cat, dan sebagainya. Manakala aspek dalaman pula merupakan keadaan komponen bangunan yang dapat dilihat setelah memasuki sesuatu ruang bangunan seperti keadaan siling, dinding dalaman, lantai, dan segala komponen yang boleh dilihat. Akhir sekali, aspek bumbung pula terdiri daripada bumbung bangunan dan segala kelengkapan bangunan yang bersangkutan dengan bumbung. 
Keadaan komponen-komponen bangunan yang diperiksa dinilai menggunakan Piawai Kod Pemeriksaan Bangunan yang diterbitkan oleh Pertubuhan Juruukur Diraja Malaysia (RISM) dan Matriks Condition Survey Protocol (CSP) 1. Kod dan protokol ini menjadi garis panduan kepada pemeriksa untuk menilai sesuatu kerosakan bangunan berdasarkan tahap kerosakan dan keutamaan komponen tersebut. Bagi memudahkan pemeriksa membuat penilaian kondisi bangunan sekolah yang diperiksa, kod dan protokol ini mempunyai sistem pemarkahan yang tersendiri (rujuk Che-Ani, 2011). Berpandukan kod ini juga, pemeriksa dapat menilai kondisi sesebuah banguan sekolah rendah dengan teliti dan secara keseluruhan.

Kerosakan atau kecacatan bangunan yang dikenalpasti adalah dinilai dan direkodkan di tapak pemeriksaan. Langkah ini bertujuan untuk memastikan penilaian yang diberikan adalah tepat dan mengelakkan berlakunya keraguan. Setiap kerosakan yang berjaya dikesan ditandakan di dalam pelan bangunan sekolah rendah. Proses ini sangat penting supaya dapat menentukan lokasi kerosakan tersebut. Selain itu, setiap kerosakan juga direkodkan dengan merakam gambar foto sebagai bahan bukti.

\subsection{Analisis data}

Setiap kerosakan yang dikenal pasti diberikan markah mengikut keadaan (condition) dan keutamaan (priority). Markah yang diperolehi menentukan tahap kerosakan tersebut sama ada baik (good), memuaskan (fair), dan teruk (dilapidated). Di samping itu, punca kerosakan tersebut juga turut dikenal pasti. Maklumat-maklumat ini direkodkan dalam bentuk Defect Sheet kemudiannya dikumpulkan dalam Shedule of Building Condition supaya dapat melihat kerosakan tersebut dalam bentuk yang lebih menyeluruh mengikut sekolah (rujuk Che-Ani, 2011).

Seterusnya, ringkasan hasil pemeriksaan seperti jumlah kerosakan, jumlah markah dan pengkadaran Matriks CSP1 bagi setiap sekolah dikumpulkan. Hasil ini dibandingkan dengan usia sekolah bagi melihat perkaitan antara keadaan sekolah dengan usia sekolah. Perbandingan ini dibentangkan dalam bentuk carta bar dan jadual.

\subsection{Keputusan Dan Perbincangan}

Penilaian terhadap kondisi fizikal bangunan sekolah rendah di bahagian Kuching telah dijalankan ke atas 24 buah sekolah. Secara keseluruhan, 4725 kerosakan bangunan berjaya dikesan dan markah terkumpul berdasarkan penilaian Matriks CSP1 adalah 45,868. Ini bermakna pengkadaran Matriks CSP1 bagi keseluruhan keadaan bangunan sekolah rendah yang diperiksa di Bahagian Kuching adalah 9.71, berada pada tahap sederhana tetapi menghampiri keadaan daif.

Bagi mengkaji perkaitan antara usia bangunan sekolah dengan jumlah kerosakan, markah dan pengkadaran, usia setiap sekolah yang diperiksa dikenalpasti (rujuk Jadual 2). Daripada sekolah yang diperiksa, 2 buah sekolah berusia di bawah 10 tahun, 5 buah sekolah berusia antara 11 hingga 20 tahun manakala 17 buah sekolah berusia lebih daripada 20 tahun. Ini menunjukkan majoriti sekolah yang diperiksa adalah berusia lebih daripada 20 tahun. 
Jadual 2: Usia bangunan sekolah yang terlibat dalam kajian

\begin{tabular}{|cc|cc|cc|cc|}
\hline $\begin{array}{c}\text { Kod } \\
\text { Sekolah }\end{array}$ & $\begin{array}{c}\text { Usia } \\
\text { Bangunan } \\
\text { (Tahun) }\end{array}$ & $\begin{array}{c}\text { Kod } \\
\text { Sekolah }\end{array}$ & $\begin{array}{c}\text { Usia } \\
\text { Bangunan } \\
\text { (Tahun) }\end{array}$ & $\begin{array}{c}\text { Kod } \\
\text { Sekolah }\end{array}$ & $\begin{array}{c}\text { Usia } \\
\text { Bangunan } \\
\text { (Tahun) }\end{array}$ & $\begin{array}{c}\text { Kod } \\
\text { Sekolah }\end{array}$ & $\begin{array}{c}\text { Usia } \\
\text { Banguna } \\
\text { (Tahun) }\end{array}$ \\
\hline SEK01 & 4 & SEK07 & 22 & SEK13 & 11 & SEK19 & 58 \\
SEK02 & 26 & SEK08 & 7 & SEK14 & 43 & SEK20 & 51 \\
SEK03 & 16 & SEK09 & 15 & SEK15 & 44 & SEK21 & 37 \\
SEK04 & 26 & SEK10 & 36 & SEK16 & 44 & SEK22 & 53 \\
SEK05 & 44 & SEK11 & 14 & SEK17 & 17 & SEK23 & 39 \\
SEK06 & 48 & SEK12 & 44 & SEK18 & 43 & SEK24 & 49 \\
\hline
\end{tabular}

\subsection{Bilangan Kerosakan Bangunan Bagi Setiap Sekolah}

Berdasarkan pemeriksaan keadaan bangunan sekolah di bahagian Kuching, sebanyak 4725 kerosakan bangunan telah dikesan di 24 buah sekolah yang terbabit dalam kajian. Jumlah kerosakan tertinggi direkodkan di SEK11 iaitu sebanyak 365 kerosakan manakala kerosakan terendah dikesan di SEK01 iaitu sebanyak 30 kerosakan. Rajah 1 menunjukkan bilangan kerosakan yang dikesan bagi setiap sekolah.

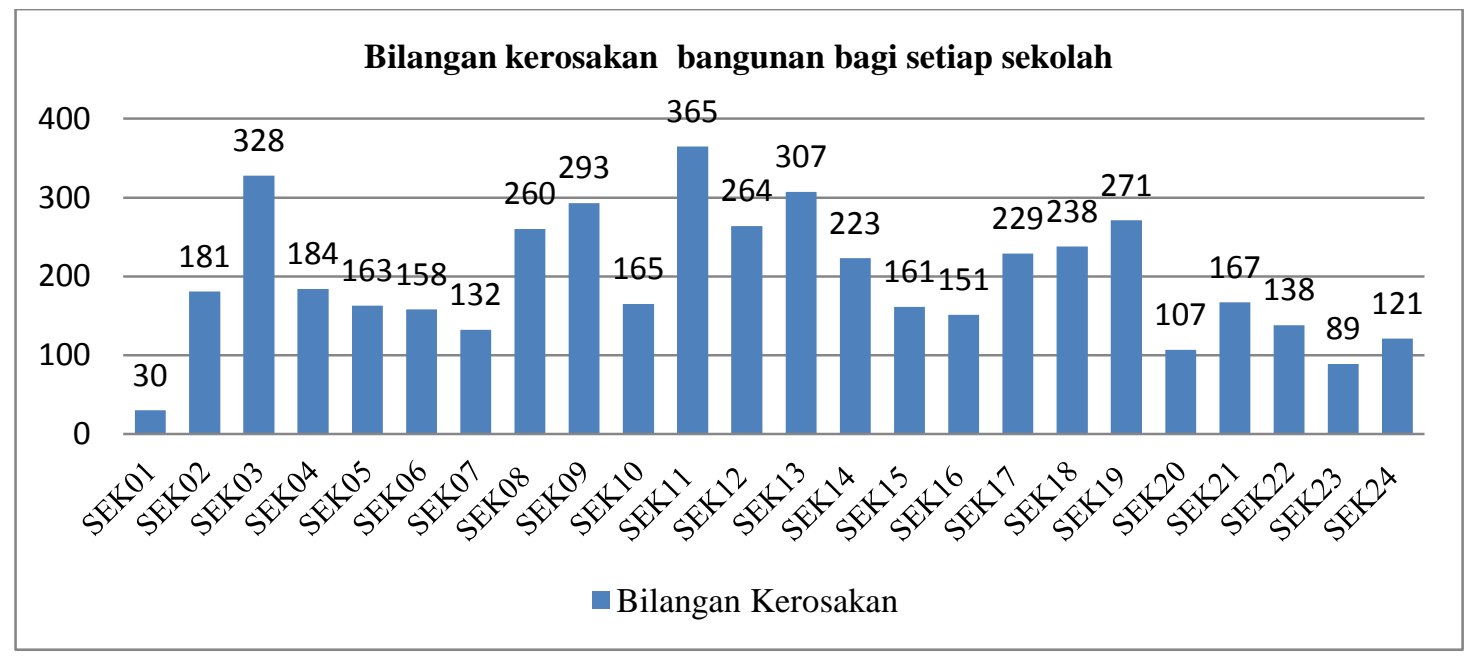

Rajah 1 :Bilangan kerosakan yang dikesan bagi setiap sekolah

Jadual 3 mempersembahkan bilangan sekolah mengikut julat usia dan bilangan sekolah mengikut jumlah kerosakan bangunan. Berdasarkan Jadual 3, jelas bahawa bangunan yang berusia lebih daripada 20 tahun mempunyai bilangan kerosakan yang tinggi dengan majoriti 12 buah sekolah mempunyai bilangan kerosakan sebanyak 100 hingga 200.

Walau bagaimanapun, bilangan kerosakan bangunan yang tertinggi direkodkan oleh sekolah-sekolah yang berusia antara 11 hingga 20 tahun. Bagi sekolah yang berada dalam lingkungan usia ini, bilangan kerosakan semua sekolah adalah melebihi 200, bahkan 3 buah daripadanya mencatatkan bilangan kerosakan tertinggi iaitu melebihi 300 
kerosakan. Senario ini boleh mewujudkan andaian bahawa kemungkinan besar kualiti bangunan yang dibina dalam tempoh waktu tersebut kurang kualiti dan mengakibatkan berlakunya banyak kerosakan, jika dibandingkan dengan sekolah yang berusia lebih 20 tahun (yang tidak mempunyai bilangan kerosakan melebihi 300).

\begin{tabular}{cccccc}
\multicolumn{6}{c}{ Jadual 3: Bilangan sekolah mengikut julat usia berbanding bilangan kerosakan bangunan } \\
\hline $\begin{array}{c}\text { Usia Sekolah } \\
\text { (Tahun) }\end{array}$ & $\begin{array}{c}\text { Bilangan } \\
\text { Sekolah }\end{array}$ & \multicolumn{6}{c}{ Bilangan Sekolah Mengikut Jumlah Kerosakan } \\
\hline & & $\mathbf{0 - 1 0 0}$ & $\mathbf{1 0 0 - 2 0 0}$ & $\mathbf{2 0 0 - 3 0 0}$ & Lebih 300 \\
\hline $1-5$ & 1 & 1 & 0 & 0 & 0 \\
$6-10$ & 1 & 0 & 0 & 1 & 0 \\
$11-15$ & 3 & 0 & 0 & 1 & 2 \\
$16-20$ & 2 & 0 & 0 & 1 & 1 \\
Lebih 20 & 17 & 1 & 12 & 4 & 0 \\
\hline Jumlah & $\mathbf{2 4}$ & $\mathbf{2}$ & $\mathbf{1 2}$ & $\mathbf{7}$ & $\mathbf{3}$ \\
\hline
\end{tabular}

\subsection{Markah Keseluruhan Kerosakan Bangunan Sekolah}

Rajah 2 menunjukkan markah keseluruhan bagi kerosakan bangunan setiap sekolah yang diperiksa berdasarkan Matriks CSP1. Markah terendah direkodkan di SEK01 iaitu 189 manakala markah tertinggi direkodkan di SEK11 dengan markah sebanyak 3795. Walaupun markah terendah yang direkodkan adalah 189, namun hanya satu sekolah yang mengumpul markah di bawah nilai 1000. Selebihnya mengumpulkan markah yang melebihi 1000.

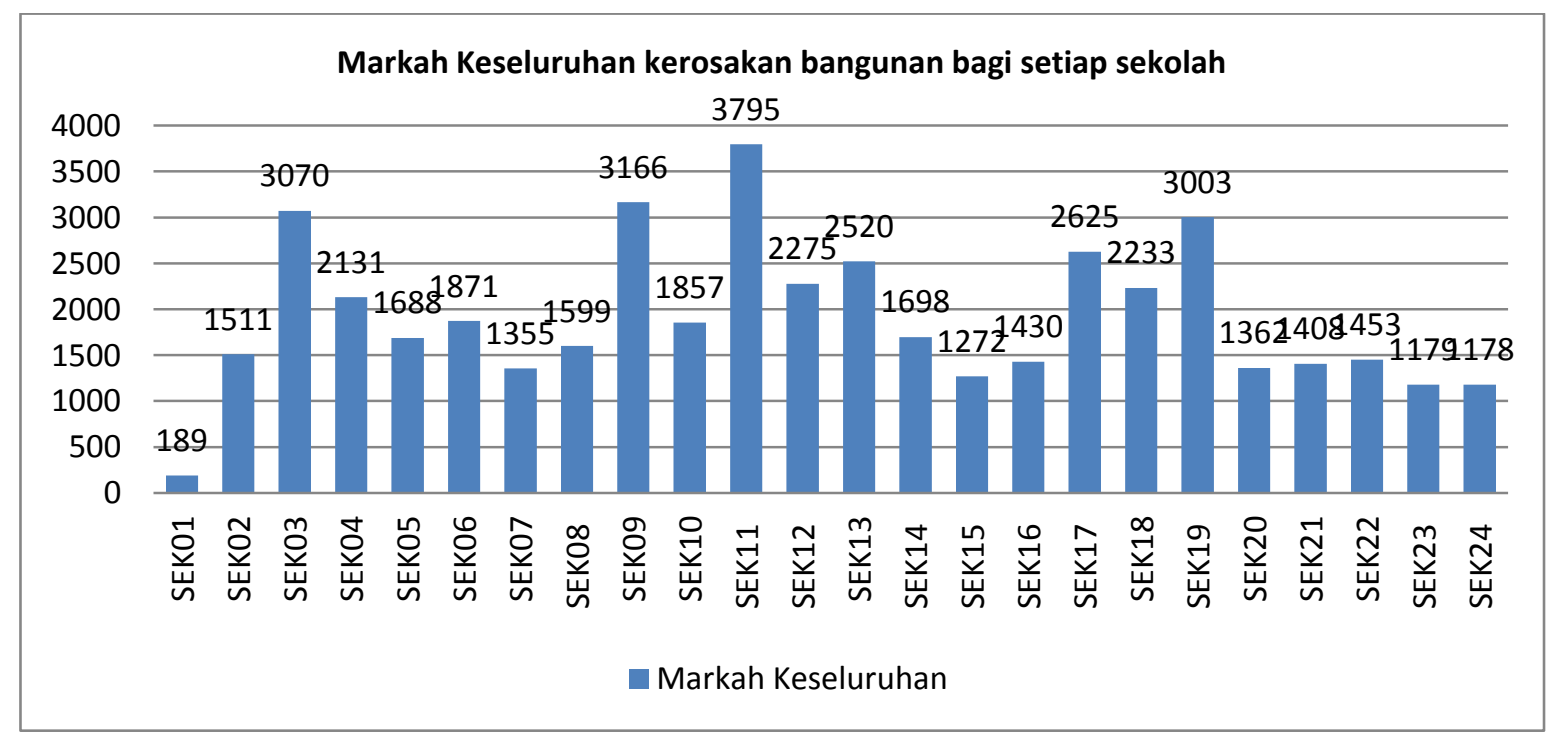

Rajah 2: Markah keseluruhan kerosakan bagi setiap sekolah

Jadual 4 menunjukkan bilangan sekolah mengikut julat usia berbanding markah yang diperolehi. Jika dibandingkan usia bangunan dengan markah keseluruhan berdasarkan Matriks CSP1 bagi setiap sekolah, majoriti sekolah memperolehi markah antara 1000-2000 iaitu sebanyak 14 buah sekolah. Daripada 14 buah sekolah ini, 13 buah sekolah berada dalam kumpulan sekolah yang berusia lebih daripada 20 tahun. Seterusnya 5 buah sekolah mendapat markah di antara 2001-3000, 4 buah sekolah mendapat markah lebih daripada 3000 dan hanya sebuah sekolah 
mendapat markah di antara 0-1000. Daripada 4 buah sekolah yang mendapat markah tertinggi iaitu lebih daripada 3000, 3 buah sekolah adalah berada dalam lingkungan usia 11-20 tahun. Keputusan ini sekali lagi menunjukkan sekolah yang berusia antara 11-20 tahun mempunyai kerosakan yang serius.

Jadual 4: Bilangan sekolah mengikut julat usia berbanding markah yang diperolehi

\begin{tabular}{cccccc}
\hline $\begin{array}{c}\text { Usia Sekolah } \\
\text { (Tahun) }\end{array}$ & $\begin{array}{c}\text { Bilangan } \\
\text { Sekolah }\end{array}$ & \multicolumn{4}{l}{ Bilangan Sekolah Mengikut Markah Matriks CSP1 } \\
\hline & & $\mathbf{0 - 1 0 0 0}$ & $\mathbf{1 0 0 1 - 2 0 0 0}$ & $\mathbf{2 0 0 1 - 3 0 0 0}$ & Lebih 3000 \\
\hline $1-5$ & 1 & 1 & 0 & 0 & 0 \\
$6-10$ & 1 & 0 & 1 & 0 & 0 \\
$11-15$ & 3 & 0 & 0 & 1 & 2 \\
$16-20$ & 2 & 0 & 0 & 1 & 1 \\
Lebih 20 & 17 & 0 & 13 & 3 & 1 \\
\hline Jumlah & $\mathbf{2 4}$ & $\mathbf{1}$ & $\mathbf{1 4}$ & $\mathbf{5}$ & $\mathbf{4}$ \\
\hline
\end{tabular}

\subsection{Pengkadaran Keseluruhan Matriks CSP1}

Rajah 3 menunjukkan pengkadaran Matriks CSP1 bagi setiap sekolah yang diperiksa. Berdasarkan rajah tersebut, pengkadaran terendah adalah 6.15 direkodkan di SEK08 manakala pengkadaran tertinggi adalah 13.25 direkodkan pada SEK23. Nilai ini menunjukkan bahawa keadaan sekolah yang paling baik adalah pada keadaan sederhana yang memerlukan pemantauan dan keadaan sekolah yang paling daif adalah pada situasi yang memerlukan pemerhatian yang serius. Rajah 3 dan Jadual 5 menunjukkan bilangan sekolah berdasarkan pengkadaran CSP1 keadaan bangunan setiap sekolah.

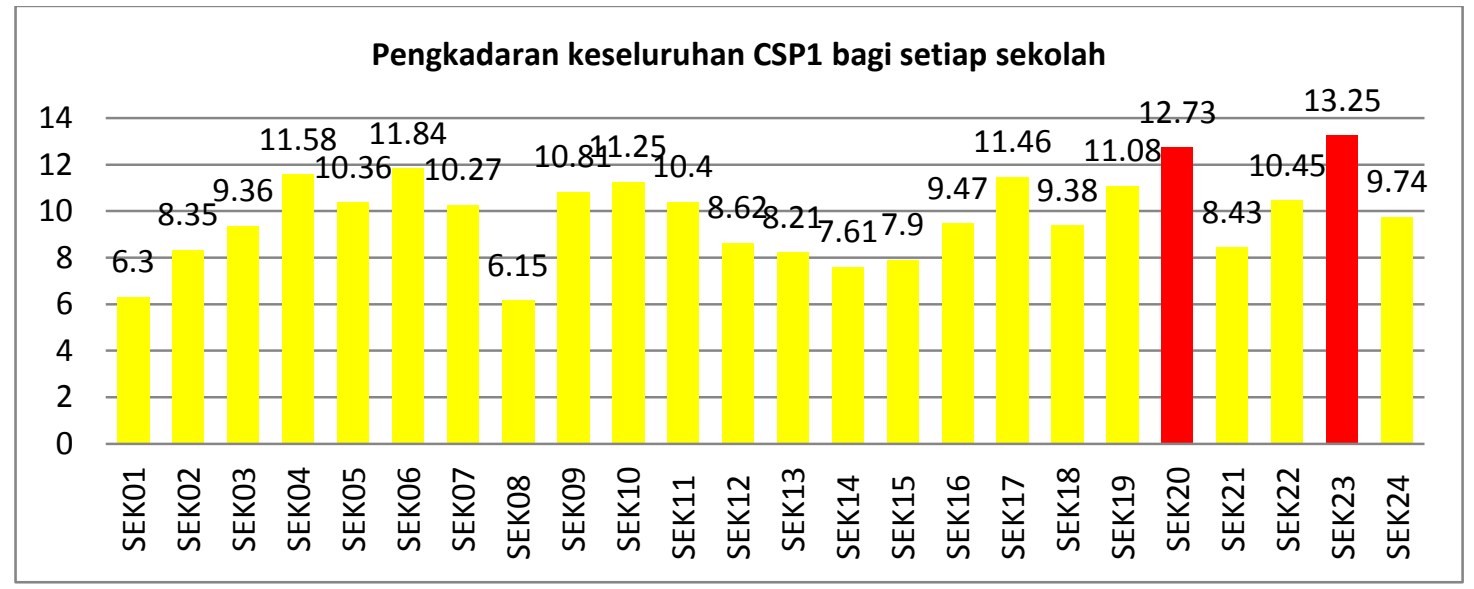

Rajah 3: Pengkadaran CSP1 bagi setiap sekolah

Jika dikaitkan dengan faktor usia bangunan sekolah, tiada sekolah yang berada dalam keadaan yang baik daripada setiap julat usia (Jadual 5). Majoriti 22 buah sekolah berada dalam keadaan sederhana manakala 2 buah sekolah berada dalam keadaan daif. Sekolah-sekolah yang berada dalam keadaan daif tersebut adalah berada dalam kumpulan usia lebih daripada 20 tahun. Figura ini menjelaskan bahawa walaupun sekolah yang mempunyai bilangan 
kerosakan yang paling tinggi adalah sekolah-sekolah yang berusia antara 11 hingga 20 tahun, namun kerosakan yang dimiliki adalah kerosakan yang sederhana yang memerlukan pemantauan dan penyenggaraan berjadual. Sebaliknya, bagi sekolah-sekolah yang berusia lebih daripada 20 tahun (yang berada dalam keadaan daif), walaupun tidak mempunyai bilangan kerosakan yang tinggi, kerosakan yang dimiliki adalah serius dan memerlukan penyenggaraan segera.

Jadual 5 :Bilangan sekolah mengikut julat usia berbanding markah yang diperolehi

\begin{tabular}{ccccc}
\hline $\begin{array}{c}\text { Usia Sekolah } \\
\text { (Tahun) }\end{array}$ & $\begin{array}{c}\text { Bilangan } \\
\text { Sekolah }\end{array}$ & \multicolumn{3}{c}{ Bilangan Sekolah Mengikut Pengkadaran Matriks } \\
CSP1
\end{tabular}

\subsection{Teori faktor usia sekolah terhadap kerosakan bangunan}

Bagi mengkaji teori mengenai faktor usia sekolah terhadap kerosakan bangunan, perkaitan antara tiga aspek yang dinilai iaitu bilangan kerosakan, markah keseluruhan dan pengkadaran keseluruhan dengan usia sekolah adalah dinilai. Jadual 6 menunjukkan perkaitan antara usia sekolah dengan ketiga-tiga aspek tersebut.

Jadual 6 : Perkaitan antara teori dengan aspek penilaian terhadap bangunan sekolah

\begin{tabular}{|c|c|c|c|c|}
\hline No & Teori & $\begin{array}{l}\text { Bilangan } \\
\text { Kerosakan }\end{array}$ & $\begin{array}{c}\text { Markah } \\
\text { Keseluruhan }\end{array}$ & $\begin{array}{l}\text { Pengkadaran } \\
\text { Keseluruhan }\end{array}$ \\
\hline 1 & $\begin{array}{c}\text { Semakin tinggi usia sekolah, } \\
\text { semakin banyak kerosakan } \\
\text { bangunan. }\end{array}$ & Berkaitan & Berkaitan & Berkaitan \\
\hline 2 & $\begin{array}{c}\text { Usia kritikal sekolah ialah antara } \\
\text { usia 11-20 tahun. }\end{array}$ & Berkaitan & Berkaitan & Tidak Berkaitan \\
\hline
\end{tabular}

Melalui analisis Matriks CSP1 dan Jadual 6, dapat dinyatakan perkaitan antara teori usia sekolah dengan aspek penilaian terhadap bangunan sekolah. Secara asasnya, semakin tinggi usia sekolah, semakin banyak kerosakan bangunan yang berlaku, dan usia kritikal sekolah yang banyak berlaku kerosakan adalah antara usia 11-20 tahun.

\subsection{Kesimpulan}

Kerja-kerja penyenggaraan bangunan sekolah di Malaysia adalah suatu yang penting dalam memastikan nilai aset negara dapat dikekalkan di samping menyediakan persekitaran yang kondusif bagi proses pengajaran dan 
pembelajaran. Hal ini telah terbukti dengan adanya kajian-kajian terdahulu sama ada dari dalam mahupun luar negara.

Hasil pemeriksaan keadaan bangunan sekolah di bahagian Kuching menunjukkan kelemahan sistem penyenggaraan bangunan sekolah di Malaysia. Pengkadaran Matriks CSP1 bagi keseluruhan sekolah yang mencecah nilai 9.71 adalah membimbangkan. Nilai ini mewujudkan persoalan mengenai kualiti persekitaran pembelajaran yang disediakan di negara ini. Nilai tersebut menunjukkan bahawa keadaan bangunan sekolah yang diperiksa tidak menyediakan keadaan pembelajaran yang kondusif. Sebagai tempat untuk menimba ilmu dan melahirkan generasi akan datang, persekitaran sekolah haruslah kondusif dan selamat untuk digunakan.

Perkaitan antara kerosakan bangunan dan usia sekolah adalah semakin tinggi usia sekolah, semakin banyak kerosakan bangunan yang berlaku. Selanjutnya, sekolah yang berada dalam lingkungan usia 11-20 tahun adalah sekolah yang bermasalah. Pada usia tersebut, jumlah kerosakan bangunan adalah tinggi. Senario ini juga menimbulkan persoalan seperti kualiti kerja pembinaan sekolah pada waktu tersebut dan usia tersebut merupakan usia kritikal bangunan. Walau bagaimanapun, kebanyakan kerosakan bangunan yang serius dikenal pasti berlaku di sekolah-sekolah yang berusia lebih daripada 20 tahun.

\subsection{Rujukan}

Abdul Lateef, O. A., Khamidi, M. F., dan Idrus, A. (2011) Appraisal of The Building Maintenance Management Practices of Malaysian Universities. Journal of Building Appraisal. 6 3/4:261-275.

Che-Ani A.I., Tazilan A.S.M., Kosman K.A. (2011) The Development of a Condition Survey Protocol Matrix. Structural Survey. 29(1):35-45.

GAO (2011) Opportunities to Reduce Potential Duplication in Government Programs, Save Tax Dollars, and Enhance Revenue. Report to Congressional Addressees. United States Government Accountability Office. Mac 2011.

Kementerian Pelajaran Malaysia (2010) Statistik Bilangan Sekolah. Laman web Kementerian Pelajaran Malaysia. Akses: 22 Ogos 2010. Kemaskini: 20 Ogos 2010.

Nik Elyna M., Kamaruzzaman S. N., dan Pitt, M. (2011) Measuring The Performance of Office Buildings Maintenance Management in Malaysia. Journal of Facilities Management. 9(3):181-199.

Schneider, M. (2002) Do School Facilities Affect Academic Outcomes? National Clearinghouse for Educational Facilities. Washington D.C.

Schneider, M. (2003) Linking School Facility Conditions to Teacher Satisfaction and Success. National Clearinghouse for Educational Facilities. Washington D.C.

Syamilah, Y. (2005) Maintenance Management System through Strategic Planning for Public School in Malaysia. Tesis Sarjana Sains (Pengurusan Pembinaan). Universiti Teknologi Malaysia.

Uline, C. dan Tschannen-Moran, M. (2008) The Wall Speak: The Interplay of Quality Facilities, School Climate, and Student Achievement. Journal of Education Administration. 46(1):56-73.

Uline, C., Tschannen-Moran, M. dan Wolsey, T. D. (2009) The Wall Still Speak: The Stories Occupant Tell. Journal of Education Administration. 47(3):400-426. 